\title{
Central Giant Cell Granuloma of Maxilla: A Case Report
}

\author{
C. Padmavathi Devi · T. Swaroopkanth • G. Sudhakar • \\ D. Kiranmai $\cdot$ R. Sasank $\cdot$ D. Sridharreddy
}

Received: 28 February 2012/ Accepted: 1 March 2012/Published online: 21 March 2012

(C) Association of Otolaryngologists of India 2012

\begin{abstract}
Central giant cell granuloma formerly called as giant cell reparative granuloma is a non neoplastic proliferative lesion of unknown etiology. It occurs most commonly in mandible, but can also occur in maxilla. The case described here involved maxilla which was treated with surgical excision.
\end{abstract}

Keywords Granuloma - Giant cells ·

Hyperparathyroidism

\section{Introduction}

Central giant cell granuloma (CGCG) was an uncommon lesion that is not a true neoplasm, but rather a reactive process. Jaffee originally coined the term giant cell reparative granuloma to describe a lesion he believed represented a response to intraosseous hemorrhage from jaw trauma. Other researches prefer the term giant cell granuloma to describe this lesion noting the inconsistent history

C. Padmavathi Devi $(\bowtie) \cdot$ R. Sasank

Department of Pathology, Siddhartha Medical College,

Vijayawada, India

e-mail: drcpd60@gmail.com

T. Swaroopkanth $\cdot$ D. Sridharreddy

Department of ENT, Siddhartha Medical College,

Vijayawada, India

G. Sudhakar

Department of Oral Maxillofacial Surgery,

Government Dental Hospital and College, Vijayawada, India

D. Kiranmai

Department of Pathology, Rangaraya Medical College,

Kakinada, India of trauma and lack of significant elements of reparative tissue.

Though defined histologically as benign lesions giant cell granuloma have the capacity for local destruction. Thus, a treatment modality that would arrest the growth is mandatory. A case of CGCG of maxilla is described.

\section{Case History}

A 40-year-old female patient presented with swelling on the right side of face for 3 months. It was insidious in the onset and later progressed to the present size.

Physical examination showed swelling on right side of face resulting in facial asymmetry (Fig. 1). The swelling was not associated with any systemic symptoms or local rise of temperature. The lesion was firm and non tender.

Routine lab investigations including serum calcium, phosphorous and alkaline phosphatase were with in normal limits.

Plain X-ray showed soft tissue mass in the right nasal cavity extending into the right maxillary sinus. No evidence of bone expansion or lysis (Fig. 2).

Direct coronal CT scan reveals a lesion with soft-tissue attenuation and several small foci of mineralization (Fig. 3).

Axial CT scan revealed soft tissue window demonstrating the expansile lesion involving the left maxillary bone. In the absence of signs of aggression and in the absence of an obvious "cystic lesion", this appearance is suggestive of CGCG. Basing on the clinical features hemimaxillectomy was performed.

We received hemimaxillectomy specimen measuring $6 \times 6 \times 4 \mathrm{~cm}$. Cut section showed a gray white lesion extending up to the edge of the resection margin with no lesion free area (Fig. 4). 


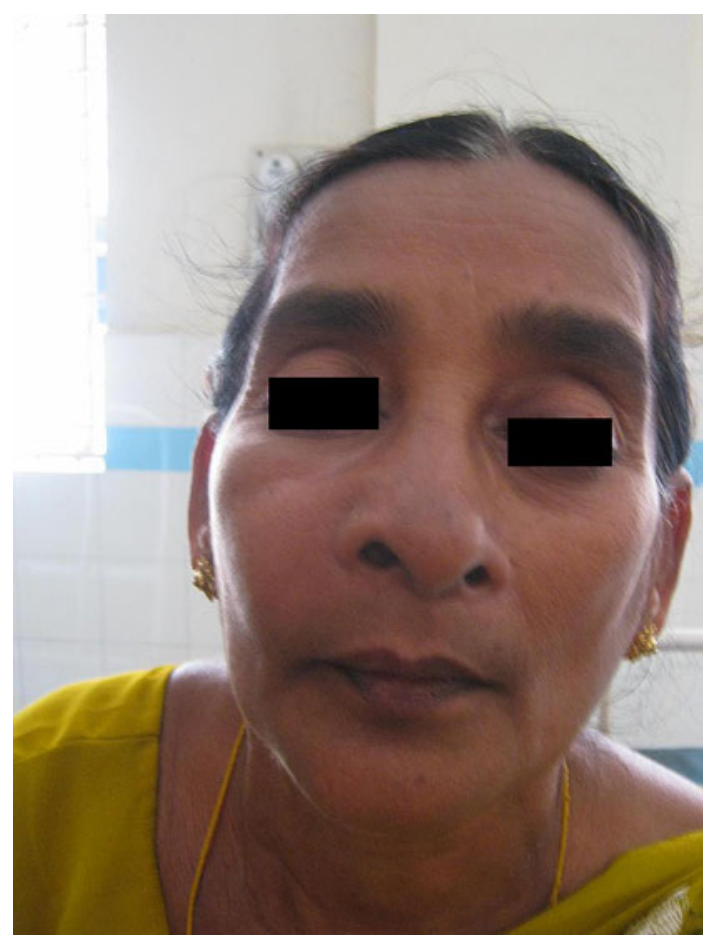

Fig. 1 Showing swelling on the right side of the face

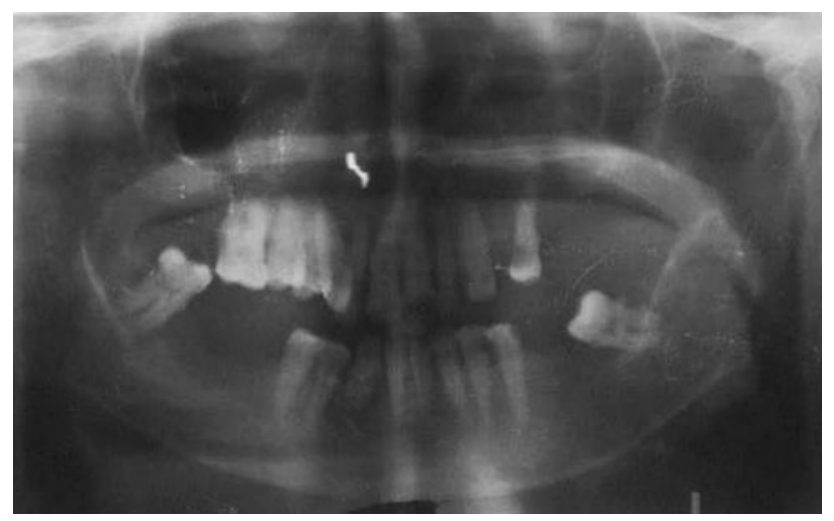

Fig. 2 Plane X-ray showing soft tissue mass in the right nasal cavity

Histopathological examination showed proliferating fibroblastic stroma intermingled with osteoclastic giant cells (Fig. 5). Areas of hemorrhage were seen and the giant cells were clustered around the areas of hemorrhage (Fig. 6). Osteoid was also identified. A diagnosis of CGCG was made.

Conventional giant cell tumor was excluded basing on the absence of spatial distribution of giant cells, smaller number of nuclei in giant cells and presence of osteoid and hemorrhages. Diffuse sheets of large giant cells and polygonal mononuclear cells are seen in giant cell tumor.

Aneurysmal bone cyst was excluded by the absence of honeycomb blood filled spaces with a lining of flat non-

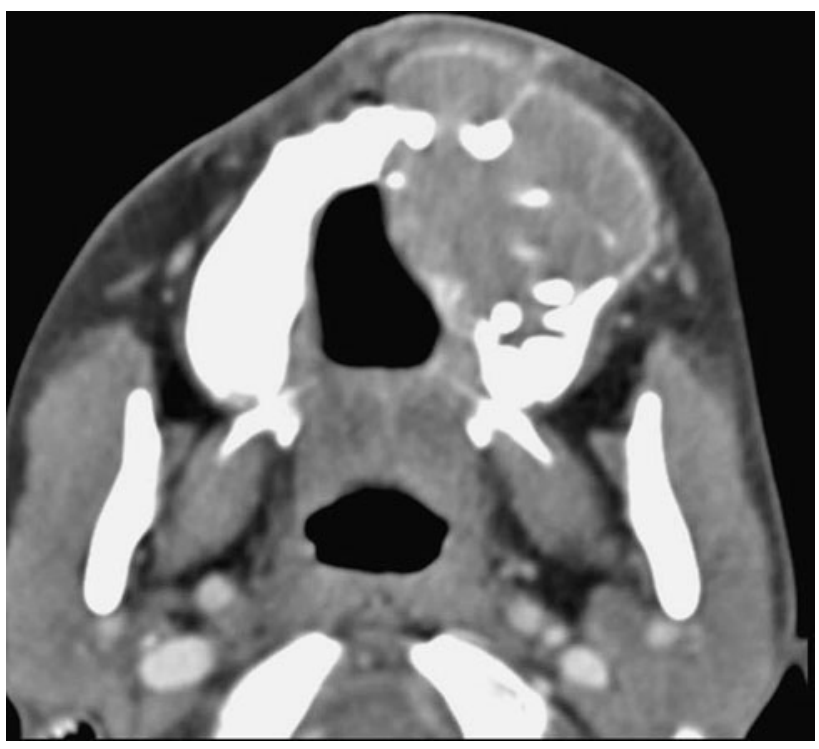

Fig. 3 CT scan showing expansile lesion in maxilla

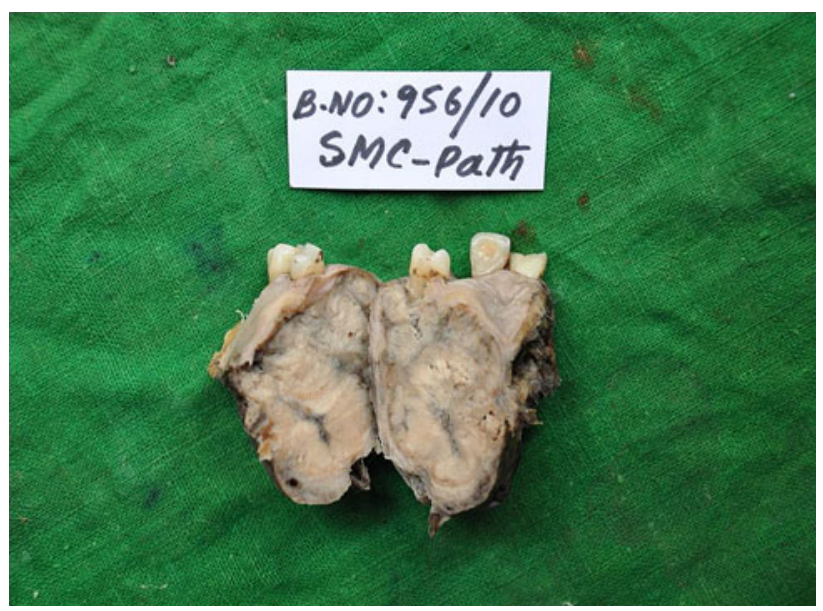

Fig. 4 Hemimaxillectomy specimen showing grey white lesion

endothelial cells. Brown tumor of hyperparathyroidism was excluded basing on age, clinical features, and laboratory investigations. Thus, all the patients with suspected CGCG should have serum calcium, phosphorous and alkaline phosphatase levels evaluated to exclude the possibility of hyperparathyroidism.

The lesion recurred 6 months after surgery which was also excised. Histopathological examination showed similar features.

\section{Discussion}

Central giant cell granuloma is a non neoplastic proliferation of unknown etiology. It occurs most commonly on 


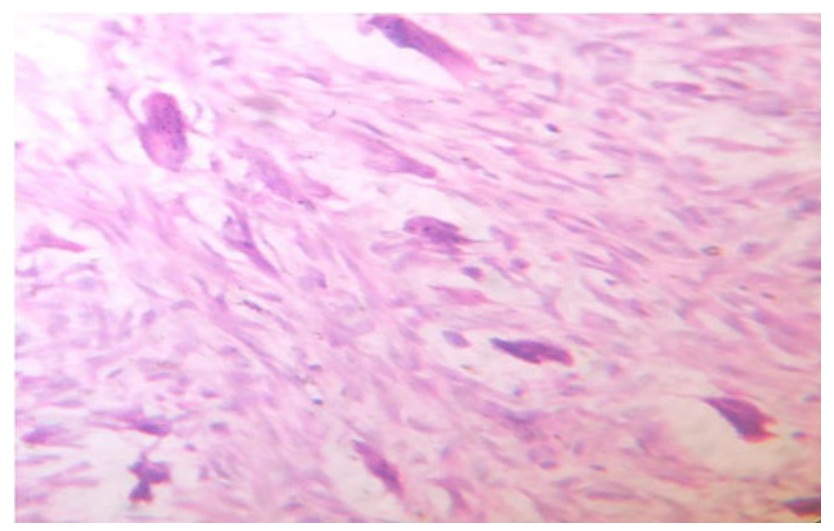

Fig. 5 Osteoclastic giant cells admixed with fibroblastic stroma

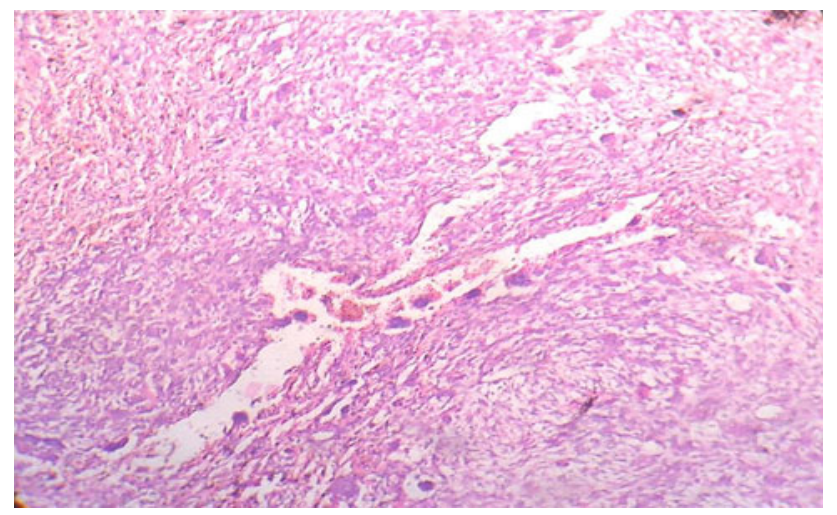

Fig. 6 Areas of hemorrhage with giant cells

the mandible than in Maxilla. CGCG accounts for less than $7 \%$ of all benign lesions of mandible and maxilla. These lesions occur 2-3 times more frequently in mandible than in maxilla [1]. It occurs more commonly on right side than on left side [1]. They generally occur in patients in 2nd and 3 rd decades of life. But can occur from infants to 7 th decade of life. $74 \%$ of the patients are under 30 years at the time of presentation [2]. It is 2-3 times common in female than in males but, there is no apparent explanation for female preponderance. They have been reported in other in parts of a body including small bones, skull, spine, clavicle, tibia, humerus, and ribs [3]. Peripheral type was four times more common than central type and is seen in middle aged and elderly patients [4]. Non specific pain and swelling are the most common clinical manifestations [4]. Multiple lesions are rare but have been reported. But, when multiple lesions occur investigations should be done to rule out hyperparathyroidism. Trauma has been considered as important etiological factor for the initiation of lesion. Radiologically CGCG appears as non specific, multiloculated lesions which due to slow growth cause thinning and scalloping of cortex, which, however is rarely breached [5]. Sometimes aggressive lesions may be present with bone destruction $[3,5]$.

CT scan is excellent for demonstration of bone thinning or destruction. MRI is the best modality of evaluating the extent of the lesion. It has low to intermediate intensity signals on both $\mathrm{T} 1 \mathrm{~W}$ and $\mathrm{T} 2 \mathrm{~W}$ images similar to GCT. Mild post enhancement is evident both on CT and MRI.

Histologically multinucleated giant cells in a cellular vascular stoma with new bone formation are detected. The osteoclast like giant cells has irregular distribution and is associated with areas of hemorrhage [6]. Ultra structurally the proliferating cells include spindle shaped fibroblasts, myofibroblasts and inflammatory mono nuclear cells $[1,6]$. The differential diagnosis includes aneurysmal bone cyst, giant cell tumor and brown tumor of hyper parathyroidism. Surgery is the traditional and most accepted form of treatment for CGCG. However, the extent of tissue removal ranges from simple curettage to unblock resection [6].

The incidence of recurrence after surgery is $4-20 \%$. The eradication of lesion does not require more than two excisions.

\section{References}

1. Walstad WR, Fields T, Schow RS, Mckenna SJ (1999) Expansile lesion of anterior maxilla. J Oral Maxillofac Surg 57:595-599

2. Sholapurkar AA, Pai KM, Ahsan A (2008) Central giant cell granuloma of the anterior maxilla. Indian J Dent Res 19(1):78-82

3. Shah UA, Shah AK, Kumar S (2006) Giant cell reparative granuloma of the jaw: a case report. Indian J Radiol Imag 16(4):677-678

4. Curtis NJ, Walker DM (2005) A case of aggressive multiple metachronous central giant cell granulomas of the jaws: differential diagnosis and management options. Int J Oralmaxillofac Surg 34:806-808

5. Murphy MD, Nomikos GC, Flemming DF, Gannon FH et al (2001) Imaging of giant cell tumor and giant cell reparative granuloma of bone: radiologic-pathologic correlation. Radiographics 21:1283-1309

6. Ciorba A, Altissimi G, Giansanti M (2004) Giant cell granuloma of maxilla: case report. Acta Otorhinolaryngol Ital 24:26-29 